\title{
The uptake exploration of ${ }^{68}$ Ga-labeled NGR in well-differentiated hepatocellular carcinoma xenografts: Indication for the new clinical translational of a tracer based on NGR
}

\author{
YONGHENG GAO ${ }^{1 *}$, ZHENGJIE WANG ${ }^{1 *}$, XIAOWEI MA ${ }^{1}$, WENHUI MA ${ }^{1}$, MINGXUAN ZHAO $^{2}$, \\ TIANMING FU ${ }^{1}$, GUOQUAN LI ${ }^{1}$, SHENGJUN WANG ${ }^{1}$, ZHE WANG ${ }^{1}$, \\ WEIDONG YANG $^{1}$, FEI KANG ${ }^{1}$ and JING WANG ${ }^{1}$ \\ ${ }^{1}$ Department of Nuclear Medicine, Xijing Hospital, Fourth Military Medical University, Xi'an, Shaanxi 710032; \\ ${ }^{2}$ Department of Nuclear Medicine, Kunming General Hospital of the People's Liberation Army, \\ Kunming, Yunnan 650032, P.R. China
}

Received February 14, 2017; Accepted May 18, 2017

DOI: $10.3892 / o r .2017 .5933$

\begin{abstract}
F-FDG has low uptake and poor diagnostic efficiency in hepatocellular carcinoma (HCC), particularly in well-differentiated HCC. The NGR peptide selectively targets $\mathrm{CD13}$, which is overexpressed in many types of tumor cells as well as neovasculature cells. In the present study, we aimed to evaluate the feasibility of utilizing ${ }^{68} \mathrm{Ga}-\mathrm{NGR}$ to image CD13positive well-differentiated HCC xenografts. The in vitro cellular uptake, in vivo micro-PET/CT imaging and biodistribution studies of ${ }^{68} \mathrm{Ga}$-NGR and ${ }^{18} \mathrm{~F}-\mathrm{FDG}$ were quantitatively compared in SMMC-7721-based well-differentiated HCC xenografts. The human fibrosarcoma (HT-1080) and human colorectal adenocarcinoma (HT-29) xenografts were respectively used as positive and negative reference groups for CD13. The expression of CD13 was qualitatively verified by immunofluorescence staining and immunohistostaining studies. The expression levels of CD13 and glucose-6-phosphatase (G6Pase) were semi-quantitatively analyzed by western blotting. The in vitro SMMC-7721 cellular uptake of ${ }^{68} \mathrm{Ga}-\mathrm{NGR}$ was significantly higher than that of ${ }^{18} \mathrm{~F}-\mathrm{FDG}(1.23 \pm 0.11$ vs. $0.515 \pm 0.14 \% ; \mathrm{P}<0.01)$. The in vivo micro-PET/CT imaging results revealed that the uptake of ${ }^{68} \mathrm{Ga}-\mathrm{NGR}$ in SMMC7721-derived tumors was $2.17 \pm 0.21 \% \mathrm{ID} / \mathrm{g}$ (percentage of
\end{abstract}

Correspondence to: Fei Kang or Jing Wang, Department of Nuclear Medicine, Xijing Hospital, Fourth Military Medical University, 127 West Changle Road, Xi'an, Shaanxi 710032, P.R. China

E-mail: fmmukf@qq.com

E-mail: wangjing@fmmu.edu.cn

*Contributed equally

Key words: CD13, ${ }^{68} \mathrm{Ga}-\mathrm{NGR},{ }^{18} \mathrm{~F}-\mathrm{FDG}$, hepatocellular carcinoma, molecular imaging, PET/CT injected dose per gram of tissue), which was higher compared to that of ${ }^{18} \mathrm{~F}$-FDG $(0.73 \pm 0.26 \% \mathrm{ID} / \mathrm{g} ; \mathrm{P}<0.01)$; however, the tumor/liver ratio of ${ }^{68} \mathrm{Ga}-\mathrm{NGR}$ was 2 -fold higher than that of ${ }^{18} \mathrm{~F}-\mathrm{FDG}$. We concluded that the uptake of ${ }^{68} \mathrm{Ga}-\mathrm{NGR}$ was significantly higher both in vitro and in vivo than ${ }^{18} \mathrm{~F}-\mathrm{FDG}$ in the well-differentiated HCC xenografts and therefore, it is promising for further clinical translation in well-differentiated HCC PET/CT diagnosis.

\section{Introduction}

Hepatocellular carcinoma (HCC) is the leading cause of cancer-related deaths worldwide (1). Ultrasound, CT and MRI have been recommended as effective examination methods for the diagnosis of HCC, but the diagnostic efficacy of these traditional imaging methods is decreased when the lesions are smaller than $1 \mathrm{~cm}$ (2-4). Fluorine-18-labeled fluorodeoxyglucose positron emission tomography computed tomography $\left({ }^{18} \mathrm{~F}-\mathrm{FDG}\right.$ PET/CT) is an effective technique for early detection and precise staging of a variety of malignant diseases, based on the fact that most malignant tumors are glucose-avid (5). However, ${ }^{18}$ F-FDG PET/CT does not exhibit a good efficiency in detecting HCCs, particularly when they are well-differentiated (6-7). Clinical studies have revealed that the total sensitivity of ${ }^{18} \mathrm{~F}$-FDG PET/CT in HCC is only 39-64\%, and the average false-negative rate is up to $40-50 \%$ (8-9). Hence, the current guidelines do not recommend the use of ${ }^{18}$ F-FDG PET/CT imaging for the detection of HCC (1). Novel methods, such as ${ }^{18} \mathrm{~F}$-FDG dual phase delay imaging (10), and ${ }^{18} \mathrm{~F}-\mathrm{FDG}+{ }^{11} \mathrm{C}$-acetate double tracer imaging $(11,12)$, have been proposed as alternative methods to PET/CT for the detection of HCC. However, ${ }^{18} \mathrm{~F}-\mathrm{FDG}$ dual phase delay imaging is complicated to operate and time-consuming; the ${ }^{11} \mathrm{C}$ isotope has a short radioactive half-life and must be produced with a cyclotron, which greatly limits the clinical application of these methods $(10,11)$. Hence, the applicability and effectiveness of these approaches are still controversial $(13,14)$. 
The uptake of various molecular imaging tracers by the tumor is mainly determined by the differential expression of the biomarkers (15). In well-differentiated HCC, it is widely accepted that the low uptake of ${ }^{18} \mathrm{~F}$-FDG mainly results from the overexpression of glucose-6-phosphatase (G6Pase), which leads to the release of ${ }^{18} \mathrm{~F}-\mathrm{FDG}$ from the tumor cells by converting the 6-phosphoric acid-FDG back to the FDG prototype $(12,16)$. However, the low expression of glucose transporter 1 (GLUT1), which serves as the primary transporter of FDG, also decreases the uptake of ${ }^{18} \mathrm{~F}$-FDG to some degree (17). Therefore, a new PET/CT tracer that targets other molecular biomarkers rather than those related to glucose metabolism should be developed to improve the clinical applications of PET/CT for the detection of well-differentiated HCC.

CD13 is a membrane-bound exopeptidase which has been shown to be overexpressed in a variety of tumor cells and neovascular endothelial cells (18-21). Therefore, it is a potential target for cancer diagnosis and therapy (22). The high expression rate of CD13 in a variety of HCC cell lines and clinical samples has already been confirmed (23-25). The asparagine-glycine-arginine (NGR) motif has been identified as an adequate ligand for CD13, displaying high affinity and specificity (26). It has been well established that, by labelling NGR peptide with ${ }^{64} \mathrm{Cu}$ or ${ }^{68} \mathrm{Ga}$ isotopes, the efficiency and specificity of NGR probes for the PET/CT imaging of CD13-positive tumors can be improved (27-30). Therefore, we questioned whether the radio-labeled NGR probe could noninvasively image well-differentiated HCC tumors. To address this issue, we performed a direct quantitative comparative preclinical study between radio-labeled NGR and FDG probes in well-differentiated HCC tumors.

Herein, the uptakes of ${ }^{68} \mathrm{Ga}-\mathrm{NGR}$ and ${ }^{18} \mathrm{~F}-\mathrm{FDG}$ by the malignancies were compared in mouse xenograft models, bearing SMMC-7721-derived well-differentiated HCC tumors (positive for both CD13 and G6Pase). The models bearing HT-1080 tumors (CD13-positive and G6Pase-negative) and HT-29 tumors (negative for both CD13 and G6Pase) were also analyzed for comparison.

\section{Materials and methods}

Materials. The NGR peptide with the chelator 1,4,7,10tetraazacyclododecan- $N, N^{\prime}, N^{\prime \prime}, N^{\prime \prime \prime}$-tetraacetic acid (DOTA-GGGCNGRC, $\mathrm{Cys}^{4}$ and $\mathrm{Cys}^{8}$ being conjugated by a disulfide bridge) was synthesized by GL Biochem Ltd. (Shanghai, China), with a purity $>95 \%$, as confirmed by high-performance liquid chromatography (HPLC; Agilent Technologies, Santa Clara, CA, USA). ${ }^{68} \mathrm{GaCl}_{3}$ was obtained from the ${ }^{68} \mathrm{Ge}-{ }^{68} \mathrm{Ga}$ radionuclide generator (ITG Co., Munich, Germany). The cell lines SMMC-7721, HT-1080 and HT-29 were purchased from the American Type Culture Collection (ATCC; Manassas, VA, USA) and cultured in RPMI or high glucose Dulbecco's modified Eagle's medium (DMEM) culture supplemented with $10 \%$ fetal bovine serum (FBS) (all from HyClone, Logan, UT, USA) in $37^{\circ} \mathrm{C}$ humidified atmosphere containing $5 \% \mathrm{CO}_{2}$. All other reagents were commercially purchased and used without further purification.

${ }^{68} \mathrm{Ga}-\mathrm{NGR}$ synthesis. ${ }^{68} \mathrm{Ga}-\mathrm{NGR}$ was prepared using the following protocol: ${ }^{68} \mathrm{GaCl}_{3}(200 \mu \mathrm{l}, 111-148 \mathrm{MBq})$ was added into DOTA-NGR $(2 \mu \mathrm{g})$, which was previously dissolved in deionized water $(2 \mu \mathrm{l})$. The $\mathrm{pH}$ value was adjusted to 4.0 by adding sodium acetate $(10 \mu \mathrm{l}, 1.25 \mathrm{M})$. The mixture obtained was subsequently incubated at $90-100^{\circ} \mathrm{C}$ for $10 \mathrm{~min}$.

The radiochemical purity ( $\mathrm{RCP}$ ) was analyzed by the mean of HPLC. The analytic HPLC experiment was performed using a RP C18 column (Zorbax; $5 \mu \mathrm{m}, 4.6 x 250 \mathrm{~mm}$ ). The HPLC method employed is described below: solvent A consisted of $0.05 \%$ trifluoroacetic acid (TFA) in water, and solvent B consisted of $0.05 \%$ TFA in acetonitrile. The flow rate was set to $1 \mathrm{ml} / \mathrm{min}$; and the gradient was $0-3 \mathrm{~min}, 5-5 \%$ solvent $\mathrm{B}$; 3-20 min, 5-65\% solvent B. All experiments were repeated four times under the same conditions.

Western blot analysis. After the cultures (HT-1080, SMMC7721 and HT-29) were subjected to the lysis process, the protein samples were quantified by bicinchoninic acid (BCA) assay and heated up at $95^{\circ} \mathrm{C}$ for $10 \mathrm{~min}$, followed by the loading buffer addition. The samples, each containing $40 \mu \mathrm{g}$ proteins, were loaded onto sodium dodecyl sulfate-polyacrylamide gel in the electrophoresis gels and transferred to polyvinylidene fluoride membrane filters (Life Technologies, Foster City, CA, USA). The membranes were blocked for $2 \mathrm{~h}$ in Tris-buffered saline containing $0.01 \%$ Tween-20 (TBST) and 5\% bovine serum albumin. Afterwards, an overnight incubation process at $4^{\circ} \mathrm{C}$ was accomplished, having the appropriate primary antibodies in TBST with $2.5 \%$ bovine serum albumin as following: mouse anti-CD13 (1:100; Santa Cruz Biotechnology, Santa Cruz, CA, USA), rabbit anti-G6Pase (1:1,000), rabbit anti-GLUT1 (1:1,000) (both from Abcam, Cambridge, MA, USA) and anti- $\beta$-actin antibodies (loading control; Beijing Biosynthesis Biotechnology Co., Ltd., Beijing, China). After $1 \mathrm{~h}$ of incubation with the peroxidase-conjugated secondary antibody (1:5,000; ZSGB-BIO, Beijing, China), the membranes were washed with TBST. The blots were developed with an enhanced chemiluminescence kit (Thermo Scientific), and images were acquired using a ChemiDOC XRS+ instrument (Bio-Rad, Hercules, CA, USA).

The relative expression levels of detected proteins were quantified in accordance with a previously reported method (31). The statistics were acquired based on four repeated experiments.

Cell uptake studies. For the cellular uptake studies, the incubation of SMMC-7721, HT-1080 and HT-29 cells was carried out in plastic tubes, with a volume of $450 \mu \mathrm{l}$ containing $5 \times 10^{5}$ cells. This was followed by the addition of $50 \mu \mathrm{l}(37 \mathrm{kBq}){ }^{68} \mathrm{Ga}-\mathrm{NGR}$ or ${ }^{18} \mathrm{~F}$-FDG into each tube. The incubation process was carried out at $37^{\circ} \mathrm{C}$ for $30,60,90$ and $120 \mathrm{~min}$. Afterwards, cold phosphate-buffered saline (PBS) was added to the mixture and centrifuged to discard the supernatant. For the cell blocking studies, SMMC-7721 cultures were incubated along with ${ }^{68} \mathrm{Ga}-\mathrm{NGR}(50 \mu \mathrm{l}, 37 \mathrm{kBq})$ and unlabeled DOTA-NGR $(2 \mu \mathrm{l}, 10 \mu \mathrm{g} / \mu \mathrm{l})$. The dosage of unlabeled DOTA-NGR was performed as previously reported $(32,33)$. The radioactivity of the precipitate was counted using a $\gamma$-counter (with decay correction, the same below). These experiments were also repeated four times under the same conditions.

In vivo micro-PET/CT imaging studies. All the animal studies were performed according to the protocol approved by the 
A

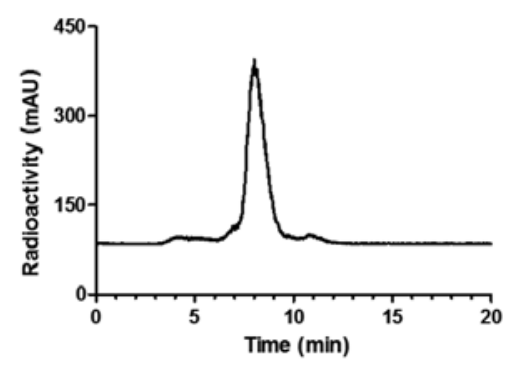

B

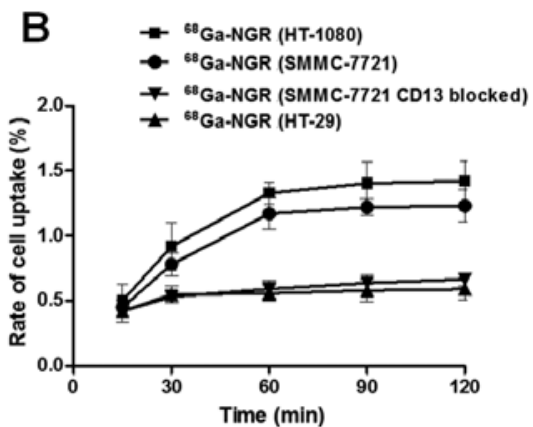

C

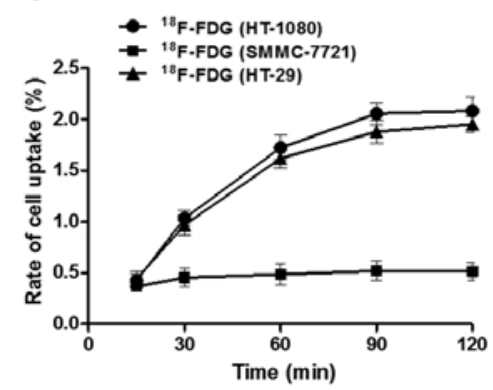

Figure 1. (A) The radio-HPLC chromatogram of ${ }^{68} \mathrm{Ga}-\mathrm{NGR}$ (retention time is $8.0 \mathrm{~min}$ ). (B) The diagram shows the uptake of ${ }^{68} \mathrm{Ga}-\mathrm{NGR}$ in HT-1080 cells, SMMC-7721 cells (including CD-13 blocked) and HT-29 cells. (C) The diagram displays the uptake of ${ }^{18}$ F-FDG in HT-1080, SMMC-7721 and HT-29 cells. $(\mathrm{n}=4$, mean $\pm \mathrm{SD})$.

Institutional Animal Care and Use Committee of the Fourth Military Medical University. Fifty-four male BALB/c nude mice (4-6 weeks old, with a body weight of 20-25 g) were used. The xenograft models were generated by administering a subcutaneously injection containing $2.5 \times 10^{6}$ tumor cells into the upper flanks of nude mice; the HT-1080 xenografts were constructed on the left scapular region of nude mice, the HT-29 and SMMC-7721 xenografts were both on the right side. The number of each type of xenograft model was 18 . The tumors were allowed to grow for 2-3 weeks until they reached a volume of $0.5-1 \mathrm{~cm}^{3}$, as required for the micro-PET/CT imaging and biodistribution experiments. The nude mice bearing SMMC-7721 tumors were randomly divided into three groups, each group including six mice, and marked as group 1,2 and 3; the same treatments were administered to HT-1080 and HT-29 xenografts. The mice in group 1 were injected with $7.4 \mathrm{MBq}$ ${ }^{18} \mathrm{~F}-\mathrm{FDG}$ by the tail vein, and the images were eventually acquired at 30, 60 and 90 min post-injection using a microPET/CT scanner (Mediso Medical Imaging Systems, Budapest, Hungary). In contrast, the mice composing group 2 were injected with $7.4 \mathrm{MBq}{ }^{68} \mathrm{Ga}-\mathrm{NGR}$; while the mice in group 3 were administered $7.4 \mathrm{MBq}{ }^{68} \mathrm{Ga}-\mathrm{NGR}$ as well as an excessive unlabeled amount of NGR $(20 \mathrm{mg} / \mathrm{kg})$. The scanning time (30, 60 and $90 \mathrm{~min}$ ) and blocking dosage were based on previously reported procedures $(27,32)$; the rest of the steps involved were similar as for group 1. The regions of interest (ROIs) over tumors on the coronal images were carefully delineated, and the average signal levels in the ROIs were expressed as \% ID/g (percentage of injected dose per gram of tissue).

Immunofluorescence staining and immunohistostaining studies. HT-1080, SMMC-7721 and respectively HT-29 cells were planted in a 24 -well plate at a density of $5 \times 10^{4}$ cells/ well. After overnight incubation at $37^{\circ} \mathrm{C}$ in $5 \% \mathrm{CO}_{2}$, the cells were washed three times with cold PBS and fixed with $4 \%$ paraformaldehyde for $15 \mathrm{~min}$. The cells were then blocked with $3 \%$ bovine serum albumin at room temperature for $1 \mathrm{~h}$ and subsequently incubated with mouse anti-CD13 for $12-16 \mathrm{~h}$ at $4^{\circ} \mathrm{C}$ (1:200; Abcam). The cultures were washed with PBS and further incubated with a fluorescent secondary goat anti-mouse FITC-antibody (1:200; ZSGB-BIO) for $2 \mathrm{~h}$ at ambient temperature. This was followed by repeated washings (five times) and continued by the addition of 4,6-diamidino-2-phenylindole (DAPI) to the cells which were further incubated for $10 \mathrm{~min}$ to stain the nuclei. The cells were analyzed using an Olympus IX71 fluorescence microscope (Olympus, Tokyo, Japan).

The mice were sacrificed by cervical dislocation, then HT-1080, SMMC-7721 and HT-29 cell-derived tumor tissues were fixed with $4 \%$ of paraformaldehyde, embedded in paraffin and sectioned at $0.3 \mu \mathrm{m}$. Then, the sections were blocked with $3 \%$ serum for $30 \mathrm{~min}$ and underwent antigen retrieval by heat mediation in a citrate buffer; this was followed by incubation with mouse anti-CD13 antibody $\left(1: 100\right.$; Abcam) at $4^{\circ} \mathrm{C}$ for 16-18 $\mathrm{h}$. The sections were subsequently washed three times with PBS and incubated with the peroxidase-conjugate secondary antibody (1:500; goat anti-mouse $\mathrm{IgG}$ for mouse anti-CD13; ZSGB-BIO) at room temperature for $1 \mathrm{~h}$, washed again with PBS, stained using 0.025\% 3,3'-diaminobenzidine solution in PBS, and eventually counterstained with hematoxylin. The sections were visualized by the aid of an Olympus BX51 microscope (Olympus).

Biodistribution studies. The xenograft models bearing SMMC-7721 tumors were randomly divided into two groups $(n=6)$, which were individually injected with $7.4 \mathrm{MBq}$ of either ${ }^{68} \mathrm{Ga}$-NGR or ${ }^{18} \mathrm{~F}$-FDG via the tail vein. At $30 \mathrm{~min}$ post-injection, the mice were sacrificed by cervical dislocation and their blood, tumors and the major organs (heart, lung, liver, spleen, pancreas, stomach, intestine, kidney, muscle, bone and brain) were harvested and weighed. The radioactivity of each sample was measured by $\gamma$-counter. The data collected are expressed as $\% \mathrm{ID} / \mathrm{g}$.

Statistical analysis. Quantitative data are expressed as mean \pm SD. Means were compared using one-way ANOVA and Student's t-test. P values $<0.05$ were considered to indicate a statistically significant result.

\section{Results}

${ }^{68} \mathrm{Ga}-\mathrm{NGR}$ radiochemistry properties and cell uptake studies. ${ }^{68} \mathrm{Ga}-\mathrm{NGR}$ was successfully synthesized with an RCP as high as $98.2 \pm 0.9 \%$ (Fig. 1A). The specific activity of the tracer was found to be between 55-80 MBq/nmol.

The cellular uptake studies revealed that ${ }^{68} \mathrm{Ga}-\mathrm{NGR}$ could bind to both SMMC-7721 and HT-1080 cells, but not to HT-29 cells and the CD13 blocked SMMC-7721 cells (Fig. 1B). However, ${ }^{18}$ F-FDG could be absorbed by HT-1080 and 


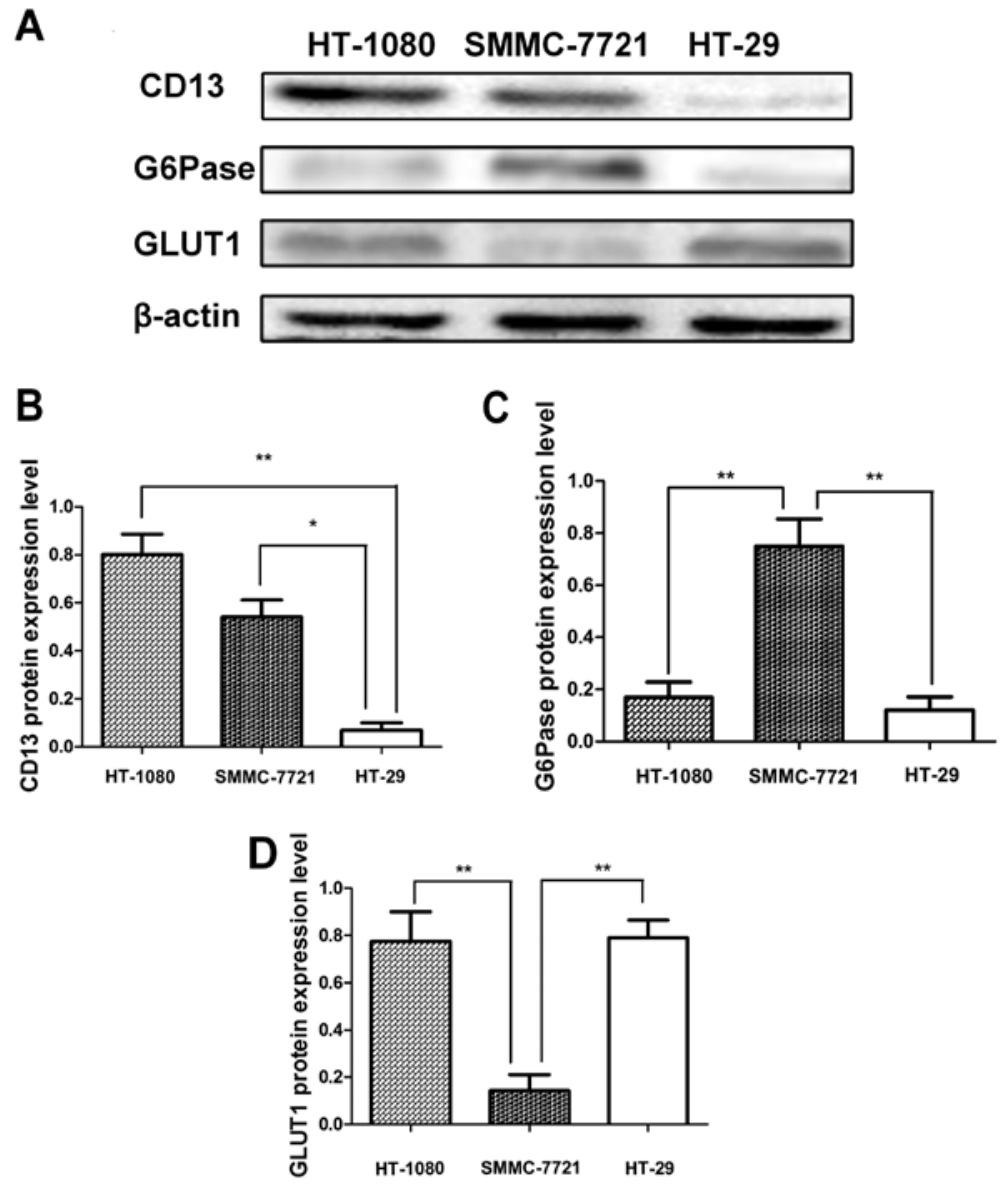

Figure 2. (A) western blot results of CD13 (150 kDa), G6Pase (40 kDa) and GLUT1 (54 kDa) in HT-1080, SMMC-7721 and HT-29 cells. (B) The semiquantitative analysis of the expression levels of CD13. (C) The semi-quantitative analysis of the expression levels of G6Pase. (D) The semi-quantitative analysis of the expression levels of GLUT $(\mathrm{n}=4$, mean $\pm \mathrm{SD}) ;{ }^{*} \mathrm{P}<0.05,{ }^{* *} \mathrm{P}<0.01$.

HT-29 cells, but not by SMMC-7721 cells (Fig. 1C). For SMMC-7721 cells, after $2 \mathrm{~h}$ of incubation, the uptake of ${ }^{68} \mathrm{Ga}-\mathrm{NGR}$ was significantly higher than that of ${ }^{18} \mathrm{~F}-\mathrm{FDG}$ $(1.23 \pm 0.11$ vs. $0.515 \pm 0.14 \%, \mathrm{P}=0.0024<0.01)$. Furthermore, after being blocked by non-radioactive NGR (CD13 blocked), the uptake of ${ }^{68} \mathrm{Ga}-\mathrm{NGR}$ in SMMC-7721 (0.59 $\left.\pm 0.08 \%\right)$ cells was significantly lower than that in non-blocked SMMC-7721 cells $(1.23 \pm 0.11 \%, \mathrm{P}=0.0013<0.01)$, which demonstrated that ${ }^{68} \mathrm{Ga}-\mathrm{NGR}$ was selectively targeting the CD13 receptor.

Western blot analysis. The western blot analysis of CD13 expression in HT-1080 and SMMC-7721 cells showed positive bands correlated to the molecular size of CD13, whereas a low signal band was observed for HT-29 cells (Fig. 2A). In addition, the western blotting analysis of G6Pase indicated that two weak bands were observed for HT-1080 and HT-29 cells, and G6Pase was expressed in the SMMC-7721 cells. The semi-quantitative analysis [the semi-quantitative analysis method based on a previously reported method (31)] results of the expression levels of CD13 (Fig. 2B), G6Pase (Fig. 2C) and GLUT1 (Fig. 2D) corresponded to our observed results. The CD13 expression levels in the HT-1080 and SMMC-7721 cells were notably higher compared to that of HT-29 $(0.80 \pm 0.12$ vs. $0.07 \pm 0.04$, $\mathrm{P}=0.0097<0.01$; and $0.54 \pm 0.10$ vs. $0.07 \pm 0.04, \mathrm{P}=0.02<0.05)$. The G6Pase expression level in the SMMC-7721 cells exhibited an obviously greater value in comparison with HT-1080 and HT-29 cells $(0.75 \pm 0.15$ vs. $0.17 \pm 0.08$, $\mathrm{P}=0.0083<0.01$; and $0.75 \pm 0.15$ vs. $0.12 \pm 0.07, \mathrm{P}=0.0085<0.01$ ). In addition, the GLUT1 expression level in SMMC-7721 cells was significantly lower than that of HT-1080 and HT-29 cells $(0.14 \pm 0.06$ vs. $0.77 \pm 0.10, \mathrm{P}=0.0098<0.01$ and $0.14 \pm 0.06$ vs. $0.79 \pm 0.06, \mathrm{P}=0.0094<0.01)$.

In vivo micro-PET/CT imaging studies. The imaging efficacies of ${ }^{18} \mathrm{~F}$-FDG and ${ }^{68} \mathrm{Ga}-\mathrm{NGR}$ were evaluated and compared in nude mice bearing HT-1080, SMMC-7721 and HT-29 xenografts by micro-PET/CT imaging (Fig. 3A). The results revealed that ${ }^{18} \mathrm{~F}$-FDG uptake in SMMC-7721 tumors was significantly lower than that in HT-1080 and HT-29 tumors $(0.73 \pm 0.26 \%$ ID $/ g$ vs. $3.47 \pm 0.31 \% \mathrm{ID} / \mathrm{g}, \mathrm{P}=0.0031<0.01$ and $0.73 \pm 0.26 \% \mathrm{ID} / \mathrm{g}$ vs. $3.17 \pm 0.29 \% \mathrm{ID} / \mathrm{g}, \mathrm{P}=0.0197<0.05)$ at $30 \mathrm{~min}$ post-injection. Regarding the uptake of ${ }^{68} \mathrm{Ga}-\mathrm{NGR}$ in SMMC-7721 tumors, it was similar to that in the CD13-positive control HT-1080 tumors $(2.46 \pm 0.23 \% \mathrm{ID} / \mathrm{g}$ vs. $2.17 \pm 0.21 \% \mathrm{ID} / \mathrm{g}, \mathrm{P}=0.18>0.05)$, and was significantly higher than that in the CD13-negative control HT-29 malignancy $(2.17 \pm 0.21 \% \mathrm{ID} / \mathrm{g}$ vs. $0.67 \pm 0.20 \%$ $\mathrm{ID} / \mathrm{g}, \mathrm{P}=0.0148<0.05)$. For SMMC-7721 tumors, the uptake of ${ }^{68} \mathrm{Ga}-\mathrm{NGR}$ was 2.97 -fold higher compared to that of ${ }^{18} \mathrm{~F}-\mathrm{FDG}$ $(2.17 \pm 0.21 \% \mathrm{ID} / \mathrm{g}$ vs. $0.73 \pm 0.26 \% \mathrm{ID} / \mathrm{g}, \mathrm{P}=0.0030<0.01)$. The corresponding quantitative analyses are showed in Fig. 3C. In addition, ${ }^{68} \mathrm{Ga}-\mathrm{NGR}$ in SMMC-7721 tumors exhibited a higher imaging efficiency than that in CD13 blocked SMMC-7721 
A $\quad$ HT-1080 (PC) SMMC-7721 HT-29 (NC)

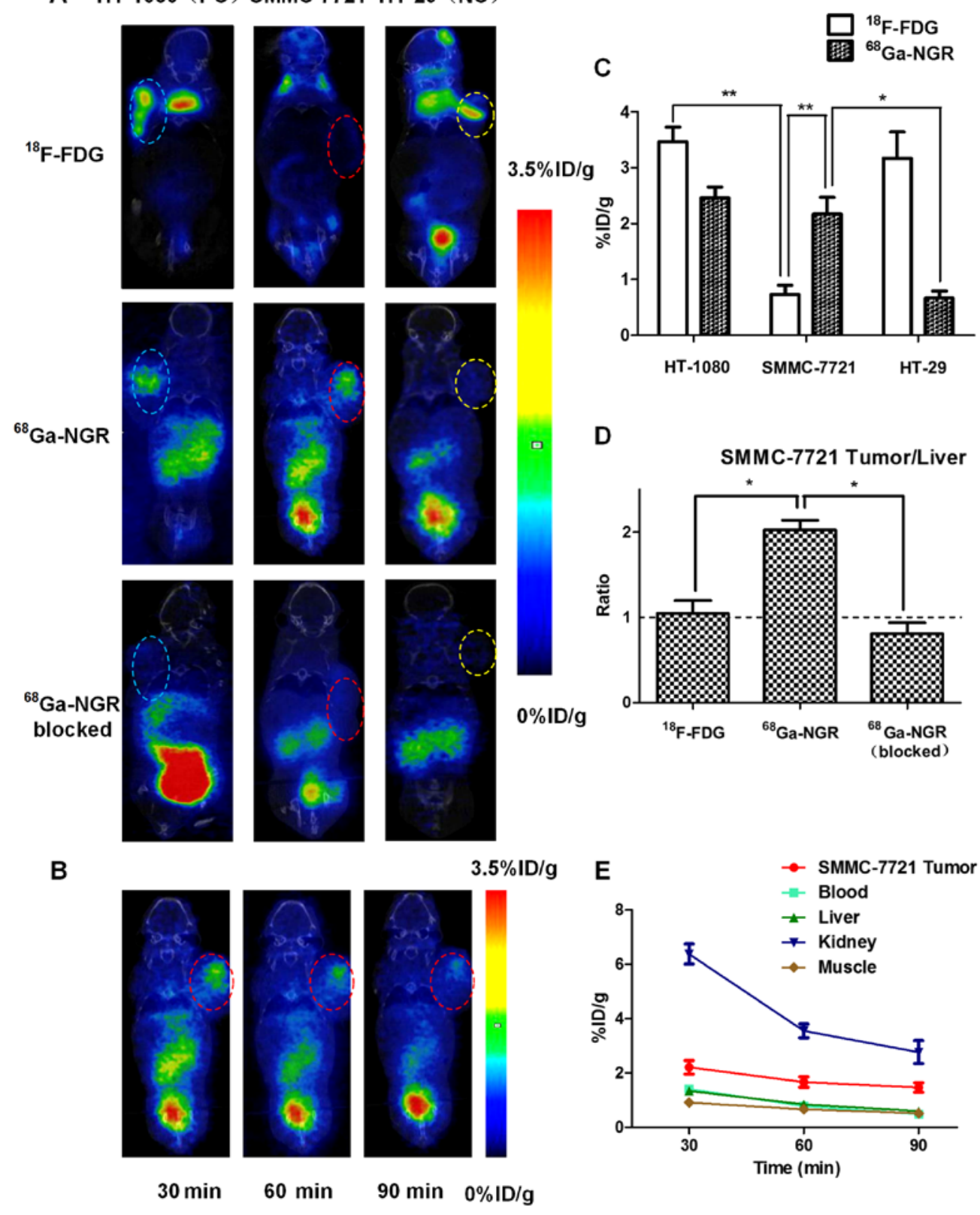

Figure 3. (A) Micro-PET/CT images at 30 min post-injection of the mice bearing HT-1080 (blue oval), SMMC-7721 (red oval) and HT-29 tumors (yellow oval) injected with ${ }^{18} \mathrm{~F}-\mathrm{FDG}(370 \mathrm{MBq} / \mathrm{kg}),{ }^{68} \mathrm{Ga}-\mathrm{NGR}(370 \mathrm{MBq} / \mathrm{kg})$ or ${ }^{68} \mathrm{Ga}-\mathrm{NGR}(370 \mathrm{MBq} / \mathrm{kg})$ blocked $(20 \mathrm{mg} / \mathrm{kg})$. PC, positive control; NC, negative control for CD13. (B) The multiple time-point micro-PET/CT imaging of mice bearing SMMC-7721 tumors (red oval) injected with ${ }^{68} \mathrm{Ga}-\mathrm{NGR}$. (C) The quantitative micro-PET/CT imaging analyses of ${ }^{18} \mathrm{~F}-\mathrm{FDG}$ and ${ }^{68} \mathrm{Ga}$-NGR in HT-1080, SMMC-7721 and HT-29 tumors. (D) The tumor/liver ratios of SMMC-7721 xenografts at $30 \mathrm{~min}$ post-injection. The dotted line indicates the tumor/liver value of ' 1 ' which means that there was no difference in the uptake between the tumor and liver. (E) Quantitative analyses of the ${ }^{68} \mathrm{Ga}-\mathrm{NGR}$ uptakes in the SMMC-7721 xenografts' major organs at different time points (n=6, mean \pm SD); ${ }^{*} \mathrm{P}<0.05,{ }^{* *} \mathrm{P}<0.01$.

tumors $(2.17 \pm 0.21 \% \mathrm{ID} / \mathrm{g}$ vs. $0.55 \pm 0.12 \% \mathrm{ID} / \mathrm{g}, \mathrm{P}=0.0078<0.01)$, which implies that ${ }^{68} \mathrm{Ga}-\mathrm{NGR}$ selectively targets CD13.

The tumor/liver (T/L) ratios of ${ }^{18} \mathrm{~F}-\mathrm{FDG}$ and ${ }^{68} \mathrm{Ga}-\mathrm{NGR}$ in SMMC-7721 xenografts at $30 \mathrm{~min}$ post-injection were calculated and are compared in Fig. 3D, and the quantitative comparison results revealed that the $\mathrm{T} / \mathrm{L}$ ratio of ${ }^{68} \mathrm{Ga}-\mathrm{NGR}$ was $2.05 \pm 0.16$, which was significantly higher than that of ${ }^{18} \mathrm{~F}$-FDG $(1.01 \pm 0.25, \mathrm{P}=0.0290<0.05)$ and ${ }^{68} \mathrm{Ga}-\mathrm{NGR}$ (CD13 blocked) $(0.81 \pm 0.18, \mathrm{P}=0.0294<0.05)$. In addition, the tumor/background $(\mathrm{T} / \mathrm{B})$ ratios of ${ }^{68} \mathrm{Ga}-\mathrm{NGR}$ in HT-1080 and HT-29 xenografts were $2.14 \pm 0.43$ and $1.18 \pm 0.25$ respectively, which indicated that ${ }^{68} \mathrm{Ga}-\mathrm{NGR}$ could image CD13+ tumors.
Multiple time-point (30, 60 and $90 \mathrm{~min}) \mathrm{micro}-\mathrm{PET} / \mathrm{CT}$ scans were performed in SMMC-7721 xenograft (Fig. 3B). The tumor uptakes of ${ }^{68} \mathrm{Ga}-\mathrm{NGR}$ were $2.17 \pm 0.21 \% \mathrm{ID} / \mathrm{g}$, $1.66 \pm 0.17 \% \mathrm{ID} / \mathrm{g}$ and $1.47 \pm 0.15 \% \mathrm{ID} / \mathrm{g}$, respectively. The dynamic uptake tendencies of ${ }^{68} \mathrm{Ga}-\mathrm{NGR}$ in major organs (blood, liver, kidneys and muscle) are shown in Fig. 3E.

Immunofluorescence staining and immunohistostaining studies. The immunofluorescence staining study indicated that CD13 was selectively expressed at the level of the cell surface of HT-1080 and SMMC-7721 tumors, but not in HT-29 cells (Fig. 4A). 
A

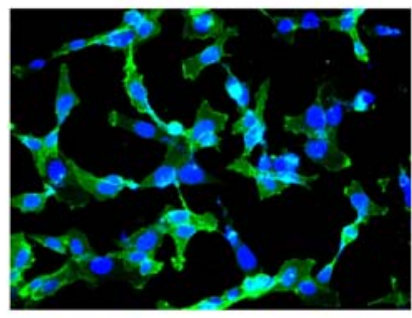

B

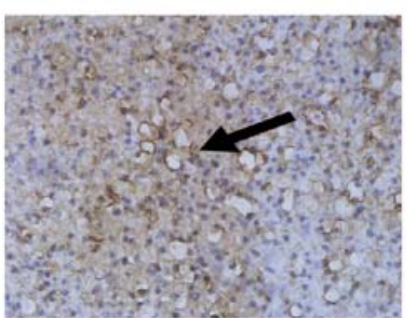

SMMC-7721
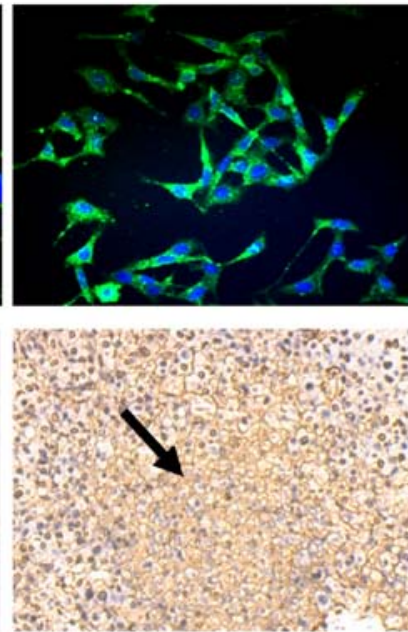

HT-29
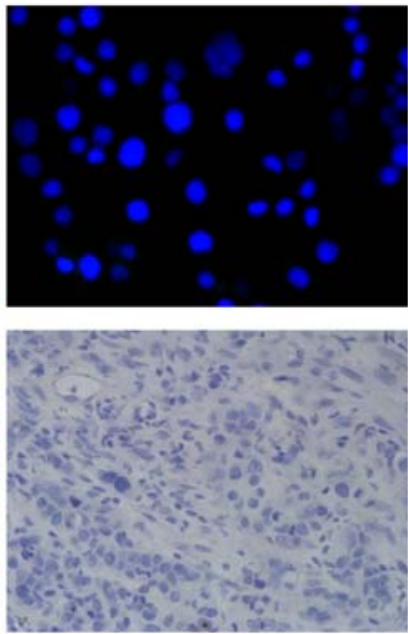

Figure 4. (A) Immunofluorescence staining of CD13 in HT-1080, SMMC-7721 and HT-29 cells. CD13 is shown in green, and the cells were co-stained in blue with DAPI for nucleus presentation (magnification, x200). (B) Immunohistostaining assays of CD13 in HT-1080 (black arrow), SMMC-7721 (black arrow) and HT-29 tumor tissues (magnification, x200).

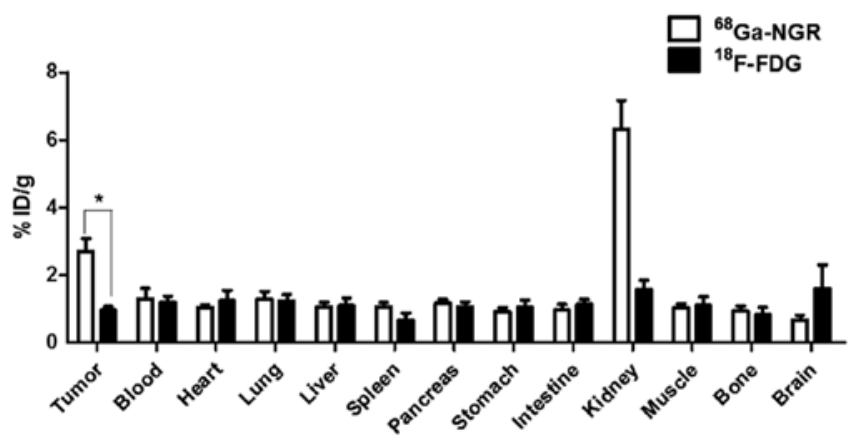

Figure 5. Biodistribution diagram of ${ }^{68} \mathrm{Ga}-\mathrm{NGR}(370 \mathrm{MBq} / \mathrm{kg})$ and ${ }^{18} \mathrm{~F}-\mathrm{FDG}$ $(370 \mathrm{MBq} / \mathrm{kg}$ ) in nude mice bearing SMMC-7721 tumors at 30 min postinjection $(\mathrm{n}=6$, mean $\pm \mathrm{SD}) ;{ }^{*} \mathrm{P}<0.05$.

The results obtained from immunohistostaining assays further indicated that CD13 was expressed on the cell surface of HT-1080 and SMMC-7721 tumor cells as well as the neovascular endothelial cells, but not in HT-29 tumor cells, which was consistent with the results obtained by western blotting analysis and immunofluorescence staining (Fig. 4B).

Biodistribution studies. The in vivo biodistribution analysis showed that, except for the kidneys, the highest accumulation of ${ }^{68} \mathrm{Ga}-\mathrm{NGR}$ was detected in SMMC-7721 HCC tumors (Fig. 5). The accumulation of ${ }^{68} \mathrm{Ga}-\mathrm{NGR}$ in SMMC-7721 HCC tumors was 2.81-fold higher compared to that of ${ }^{18} \mathrm{~F}-\mathrm{FDG}(2.70 \pm 0.65$ $\% \mathrm{ID} / \mathrm{g}$ vs. $0.96 \pm 0.19 \% \mathrm{ID} / \mathrm{g}, \mathrm{P}=0.0298<0.05)$.

\section{Discussion}

In the present study, we found that the uptake of ${ }^{68} \mathrm{Ga}-\mathrm{NGR}$ was 2.97-fold higher than that of ${ }^{18} \mathrm{~F}$-FDG by SMMC-7721 tumors, based on micro-PET/CT imaging studies, and 2.81-fold higher, based on biodistribution studies. However, the T/L ratio of ${ }^{68} \mathrm{Ga}-\mathrm{NGR}$ was 2.03 -fold higher than that of ${ }^{18} \mathrm{~F}-\mathrm{FDG}$ in the well-differentiated HCC models. These findings strongly reflected that ${ }^{68} \mathrm{Ga}-\mathrm{NGR}$ was potentially superior to ${ }^{18} \mathrm{~F}-\mathrm{FDG}$ for imaging well-differentiated HCC.

The development of radio-labeled peptide probes, such as RGD and NGR, for diagnostic and therapeutic applications, has rapidly expanded in the last decades (34-37). On the aspect of clinical practice, the safety and the applicability of these probes have been well established in lung cancer (38-40), brain metastases (41), breast cancer (42) and rheumatoid arthritis (43). Even though HCCs are worldwide malignant tumors with high incidence of morbidity, there has been little progress in their detection by radio-labeled probes. Roland et al utilized $\left[{ }^{68} \mathrm{Ga}\right.$ ]NODAGA-RGD to image patients with HCCs, but the probe uptake by the HCC tumors and the tumor/liver ratio were both insufficient for HCC detection (44). This may be attributed to the low receptor expression and the higher background radioactivity in the cirrhotic liver leading to poor detection. As the high expression of CD13 in well-differentiated HCC has been confirmed in previous studies (23-25), utilizing NGR-based probes for $\mathrm{HCC}$ detection is an attractive prospect. In the present study, the positive expression of CD13 was confirmed in SMMC7721 and HT-1080 cell-derived tumors and neovascular endothelial cells by western blot or immunohistochemical analyses. Furthermore, the high uptake and T/L ratio of ${ }^{68} \mathrm{Ga}-$ NGR in the well-differentiated HCC xenografts indicated the ability of ${ }^{68} \mathrm{Ga}-\mathrm{NGR}$ to image well-differentiated HCC. However, the high expression rate of CD13 has already been confirmed not only in a variety of HCC cell lines, but also clinical samples $(23,24)$, which suggests that ${ }^{68} \mathrm{Ga}-\mathrm{NGR}$ may have high specificity and sensitivity for further clinical diagnosis of well-differentiated HCCs. Poor-differentiated HCCs have relatively low expression of G6Pase and high expression of GLUT1 (17), which may contribute to the low uptake of ${ }^{18} \mathrm{~F}-\mathrm{FDG}$ by poor-differentiated HCC. The uptake performance of ${ }^{68} \mathrm{Ga}-\mathrm{NGR}$, in poor-differentiated $\mathrm{HCC}$, warrants further investigation.

Chronic hepatitis is the leading cause of cirrhosis and hepatocellular carcinoma (HCC) (45), and early discrimination 
of liver cirrhosis from chronic hepatitis is critical for effective treatment and optimal prognosis (46). The probe based on the RGD peptide was reported to specifically bind to integrin $\alpha v \beta 3$ receptors in activated hepatic stellate cells (HSCs). The hepatic deposition amount of RGD probe was markedly increased in parallel with the development and progression of liver fibrosis, which indicate that we could quantitatively assess the extent of liver fibrosis with probes based on RGD (47). Since CD13 has also been reported to be a highly specific marker of hepatocyte differentiation $(23,25)$, it is possible for ${ }^{68} \mathrm{Ga}-\mathrm{NGR}$ to differentiate cirrhosis from chronic hepatitis and HCCs from non-HCCs. However, how ${ }^{68} \mathrm{Ga}$-NGR specifically performs in cirrhosis or non-HCCs, such as cholangiocellular carcinoma (CCC) or focal nodular hyperplasia $(\mathrm{FNH})$, warrants further investigation.

The additional advantages of peptide-based radiopharmaceuticals, beyond ${ }^{18} \mathrm{~F}-\mathrm{FDG}$, require further exploration. In the present study, we found that for the imaging of welldifferentiated $\mathrm{HCC}$, the ${ }^{68} \mathrm{Ga}-\mathrm{NGR}$ probe was more efficient, compared to ${ }^{18} \mathrm{~F}$-FDG, in three distinct aspects, as discussed below. Firstly, the uptake of ${ }^{68} \mathrm{Ga}-\mathrm{NGR}$ was substantially higher compared to that of ${ }^{18} \mathrm{~F}$-FDG in well-differentiated HCC tumors, which indicated its potential to be used as an improved alternative to ${ }^{18} \mathrm{~F}$-FDG for the diagnosis of well-differentiated HCCs. Secondly, compared with ${ }^{64} \mathrm{Cu}$ or ${ }^{99 \mathrm{~m}} \mathrm{Tc}$-labeled NGR, reported in previous studies $(27,48),{ }^{68} \mathrm{Ga}-\mathrm{NGR}$ displayed a low uptake in liver tissue; and the $\mathrm{T} / \mathrm{L}$ ratio of ${ }^{68} \mathrm{Ga}-\mathrm{NGR}$ was $2.05 \pm 0.16$, which was significantly higher than that of ${ }^{18} \mathrm{~F}-\mathrm{FDG}(1.01 \pm 0.25),{ }^{64} \mathrm{Cu}$-labeled NGR (0.35) (27), and ${ }^{99 \mathrm{~m}} \mathrm{Tc}-$ labeled NGR (0.34) (48). Lastly, as ${ }^{68} \mathrm{Ga}$ is a cost-effective radioisotope that could be easily obtained from a ${ }^{68} \mathrm{Ge} /{ }^{68} \mathrm{Ga}$ generator, ${ }^{68} \mathrm{Ga}-\mathrm{NGR}$ peptide-based radiopharmaceuticals could be effortlessly and inexpensively produced. Altogether, these ${ }^{68} \mathrm{Ga}-\mathrm{NGR}$ properties indicate its excellent potential for clinical translation in the future.

Generally, malignant tumors are highly phenotypically and genetically heterogeneous, which is an important contributing factor for clinical diagnosis and treatment decision (49). The molecular imaging approach provides the opportunity to noninvasively visualize the expression level of molecular markers in vivo, and hence, it is superior to traditional histopathological examination (50). Based on the present study, ${ }^{68} \mathrm{Ga}-\mathrm{NGR}$ could image CD13-positive tumors (SMMC-7721 and HT-1080 tumors) and ${ }^{18} \mathrm{~F}$-FDG could image G6Pase-negative tumors (HT-1080 and HT-29 tumors), which indicates that the different uptake rates of the tracers $\left({ }^{68} \mathrm{Ga}-\mathrm{NGR}\right.$ and $\left.{ }^{18} \mathrm{~F}-\mathrm{FDG}\right)$ are closely associated with the expression levels of the corresponding molecular markers (CD13 and G6Pase, respectively). These results imply the possibility of a non-invasive molecular imaging method to evaluate the expression of corresponding biomarkers.

Despite these promising findings, the advantages of ${ }^{68} \mathrm{Ga}-\mathrm{NGR}$ in imaging efficiency have only been demonstrated in in vitro and xenograft models. More HCC cell lines and orthotopic HCC models may be explored in our future studies. However, it is vital for clinical translation studies to validate the actual effect of ${ }^{68} \mathrm{Ga}-\mathrm{NGR}$ in order to determine the specificity and sensitivity of ${ }^{68} \mathrm{Ga}-\mathrm{NGR}$ for the diagnosis of well-differentiated HCCs in the clinic.

In summary, the present study demonstrated that the uptake of ${ }^{68} \mathrm{Ga}-\mathrm{NGR}$ was significantly higher than that of ${ }^{18} \mathrm{~F}$-FDG in well-differentiated HCC xenografts and therefore ${ }^{68} \mathrm{Ga}-\mathrm{NGR}$ was more suitable for the imaging of well-differentiated $\mathrm{HCC}$, which suggests its future potential for clinical translation in the PET/CT diagnosis of HCC.

\section{Acknowledgements}

The present study was supported by the National Natural Science Foundation of China (grant nos. 81230033, 81401442 , 81227901 and 81601521), the National Key Research and Development Program of China (grant no. 2016YFC0103804), the Xijing Hospital Subject Promoting Plan (grant nos. XJZT15G01, XJZT15M07), the Shaanxi Science \& Technology Co-ordination \& Innovation Project (grant no. S2016TQSF0021) and the Shaanxi Science \& Technology Co-ordination \& Innovation Project (grant no. 2016KTCQ03-09). We would like to thank Professor Fan Wang from the Medical Isotopes Research Center of Peking University (Beijing, China) for her generous support, and Guiyu Li, Mingru Zhang and Shu Zong for their technical assistance in conducting the present study.

\section{References}

1. Jemal A, Bray F, Center MM, Ferlay J, Ward E and Forman D: Global cancer statistics. CA Cancer J Clin 61: 69-90, 2011.

2. Benson AB III, Abrams TA, Ben-Josef E, Bloomston PM, Botha JF, Clary BM, Covey A, Curley SA, D'Angelica MI, Davila R, et al: NCCN clinical practice guidelines in oncology: Hepatobiliary cancers. J Natl Compr Canc Netw 7: 350-391, 2009.

3. Kwon HJ, Byun JH, Kim JY, Hong GS, Won HJ, Shin YM and Kim PN: Differentiation of small $(\leq 2 \mathrm{~cm})$ hepatocellular carcinomas from small benign nodules in cirrhotic liver on gadoxetic acid-enhanced and diffusion-weighted magnetic resonance images. Abdom Imaging 40: 64-75, 2015.

4. Yu NC, Chaudhari V, Raman SS, Lassman C, Tong MJ, Busuttil RW and Lu DS: CT and MRI improve detection of hepatocellular carcinoma, compared with ultrasound alone, in patients with cirrhosis. Clin Gastroenterol Hepatol 9: 161-167, 2011.

5. Zhan HW, Xu W, Ye XJ, Zhao CL, Zhang H, Li J, Yao Q and Zhang LJ: Application of FDG-PET for detection of malignant lesions in patients with elevated blood tumor markers but without a history of malignancy. Mol Med Rep 2: 837-842, 2009.

6. Delbeke D, Martin WH, Sandler MP, Chapman WC, Wright JK Jr and Pinson CW: Evaluation of benign vs malignant hepatic lesions with positron emission tomography. Arch Surg 133: 510-515, 1998.

7. Iwata Y, Shiomi S, Sasaki N, Jomura H, Nishiguchi S, Seki S, Kawabe J and Ochi H: Clinical usefulness of positron emission tomography with fluorine-18-fluorodeoxyglucose in the diagnosis of liver tumors. Ann Nucl Med 14: 121-126, 2000.

8. Hayakawa N, Nakamoto Y, Nakatani K, Hatano E, Seo S, Higashi T, Saga T, Uemoto S and Togashi K: Clinical utility and limitations of FDG PET in detecting recurrent hepatocellular carcinoma in postoperative patients. Int J Clin Oncol 19: 1020-1028, 2014.

9. Chen YK, Hsieh DS, Liao CS, Bai CH, Su CT, Shen YY, Hsieh JF, Liao AC and Kao CH: Utility of FDG-PET for investigating unexplained serum AFP elevation in patients with suspected hepatocellular carcinoma recurrence. Anticancer Res 25: 4719-4725, 2005.

10. Cheng G, Torigian DA, Zhuang $\mathrm{H}$ and Alavi A: When should we recommend use of dual time-point and delayed timepoint imaging techniques in FDG PET? Eur J Nucl Med Mol Imaging 40: 779-787, 2013.

11. Park JW, Kim JH, Kim SK, Kang KW, Park KW, Choi JI, Lee WJ, Kim CM and Nam BH: A prospective evaluation of ${ }^{18} \mathrm{~F}-\mathrm{FDG}$ and ${ }^{11} \mathrm{C}$-acetate PET/CT for detection of primary and metastatic hepatocellular carcinoma. J Nucl Med 49: 1912-1921, 2008.

12. Ho CL, Yu SC and Yeung DW: ${ }^{11} \mathrm{C}$-acetate PET imaging in hepatocellular carcinoma and other liver masses. J Nucl Med 44: 213-221, 2003. 
13. Lam MG, Kwee TC, Basu S and Alavi A: Underestimated role of ${ }^{18} \mathrm{~F}$-FDG PET for HCC evaluation and promise of ${ }^{18} \mathrm{~F}$-FDG PET/MR imaging in this setting. J Nucl Med 54: 1510-1511, 2013.

14. Cheung TT, Ho CL, Chen S, Chan SC, Poon RT, Fan ST and Lo CM: Reply: Underestimated role of ${ }^{18} \mathrm{~F}$-FDG PET for HCC evaluation and promise of ${ }^{18} \mathrm{~F}-\mathrm{FDG}$ PET/MR imaging in this setting. J Nucl Med 54: 1511-1512, 2013.

15. Tichauer KM, Wang Y, Pogue BW and Liu JT: Quantitative in vivo cell-surface receptor imaging in oncology: Kinetic modeling and paired-agent principles from nuclear medicine and optical imaging. Phys Med Biol 60: R239-R269, 2015.

16. Sharma B, Martin A and Zerizer I: Positron emission tomographycomputed tomography in liver imaging. Semin Ultrasound CT MR: 34: 66-80, 2013.

17. Izuishi K, Yamamoto Y, Mori H, Kameyama R, Fujihara S, Masaki T and Suzuki Y: Molecular mechanisms of $\left[{ }^{18} \mathrm{~F}\right]$ fluorodeoxyglucose accumulation in liver cancer. Oncol Rep 31: 701-706, 2014.

18. Zhang Q, Wang J, Zhang H, Zhao D, Zhang Z and Zhang S: Expression and clinical significance of aminopeptidase N/CD13 in non-small cell lung cancer. J Cancer Res Ther 11: 223-228, 2015.

19. Wickström M1, Larsson R, Nygren P and Gullbo J: Aminopeptidase $\mathrm{N}$ (CD13) as a target for cancer chemotherapy. Cancer Sci 102: 501-508, 2011.

20. Ikeda N, Nakajima Y, Tokuhara T, Hattori N, Sho M, Kanehiro H and Miyake M: Clinical significance of aminopeptidase N/CD13 expression in human pancreatic carcinoma. Clin Cancer Res 9: 1503-1508, 2003.

21. Fukasawa K, Fujii H, Saitoh Y, Koizumi K, Aozuka Y, Sekine K, Yamada M, Saiki I and Nishikawa K: Aminopeptidase N (APN/CD13) is selectively expressed in vascular endothelial cells and plays multiple roles in angiogenesis. Cancer Lett 243 135-143, 2006.

22. Su L, Cao J, Jia Y, Zhang X, Fang H and Xu W: Development of synthetic aminopeptidase N/CD13 inhibitors to overcome cancer metastasis and angiogenesis. ACS Med Chem Lett 3: 959-964, 2012.

23. Rocken C, Licht J, Roessner A and Carl-McGrath S: Canalicular immunostaining of aminopeptidase N (CD13) as a diagnostic marker for hepatocellular carcinoma. J Clin Pathol 58: 1069-1075, 2005.

24. Nagano H, Ishii H, Marubashi S, Haraguchi N, Eguchi H, Doki Y and Mori M: Novel therapeutic target for cancer stem cells in hepatocellular carcinoma. J Hepatobiliary Pancreat Sci 19: 600-605, 2012

25. Röcken C, Carl-McGrath S, Gräntzdörffer I, Mantke R, Roessner A and Lendeckel U: Ectopeptidases are differentially expressed in hepatocellular carcinomas. Int J Oncol 24: 487-495, 2004.

26. Corti A, Curnis F, Arap W and Pasqualini R: The neovasculature homing motif NGR: More than meets the eye. Blood 112: 2628-2635, 2008.

27. Chen K, Ma W, Li G, Wang J, Yang W, Yap LP, Hughes LD, Park R and Conti PS: Synthesis and evaluation of ${ }^{64} \mathrm{Cu}$-labeled monomeric and dimeric NGR peptides for MicroPET imaging of CD13 receptor expression. Mol Pharm 10: 417-427, 2013.

28. Zhang J, Lu X, Wan N, Hua Z, Wang Z, Huang H, Yang M and Wang F: ${ }^{68} \mathrm{Ga}$-DOTA-NGR as a novel molecular probe for APN-positive tumor imaging using MicroPET. Nucl Med Biol 41: 268-275, 2014.

29. Mate G, Kertesz I, Enyedi KN, Mező G, Angyal J, Vasas N, Kis A, Szabó É, Emri M, Bíró T, et al: In vivo imaging of Aminopeptidase N (CD13) receptors in experimental renal tumors using the novel radiotracer ${ }^{68} \mathrm{Ga}-\mathrm{NOTA}-\mathrm{c}(\mathrm{NGR})$. Eur J Pharm Sci 69: 61-71, 2015.

30. Shao Y, Liang W, Kang F, Yang W, Ma X, Li G, Zong S, Chen K and Wang $\mathrm{J}$ : A direct comparison of tumor angiogenesis with ${ }^{68} \mathrm{Ga}$-labeled NGR and RGD peptides in HT-1080 tumor xenografts using microPET imaging. Amino Acids 46: 2355-2364, 2014.

31. Kang F, Ma W, Ma X, Shao Y, Yang W, Chen X, Li L and Wang J: Propranolol inhibits glucose metabolism and ${ }^{18} \mathrm{~F}-\mathrm{FDG}$ uptake of breast cancer through posttranscriptional downregulation of hexokinase-2. J Nucl Med 55: 439-445, 2014.
32. Zhao M, Yang W, Zhang M, Li G, Wang S, Wang Z, Ma X, Kang F and Wang J: Evaluation of ${ }^{68} \mathrm{Ga}$-labeled iNGR peptide with tumor-penetrating motif for microPET imaging of CD13-positive tumor xenografts. Tumour Biol 37: 12123-12131, 2016.

33. Alberici L, Roth L, Sugahara KN, Agemy L, Kotamraju VR, Teesalu T, Bordignon C, Traversari C, Rizzardi GP and Ruoslahti E: De novo design of a tumor-penetrating peptide. Cancer Res 73: 804-812, 2013.

34. Chen H, Niu G, Wu H and Chen X: Clinical application of radiolabeled RGD peptides for PET imaging of integrin $\alpha v \beta 3$. Theranostics 6: 78-92, 2016.

35. Ma W, Shao Y, Yang W, Li G, Zhang Y, Zhang M, Zuo C, Chen K and Wang J: Evaluation of ${ }^{188}$ Re-labeled NGR-VEGI protein for radioimaging and radiotherapy in mice bearing human fibrosarcoma HT-1080 xenografts. Tumour Biol 37: 9121-9129, 2016.

36. Tillmanns J, Schneider M, Fraccarollo D, Schmitto JD, Länger F, Richter D, Bauersachs J and Samnick S: PET imaging of cardiac wound healing using a novel $\left.{ }^{68} \mathrm{Ga}\right]$-labeled NGR probe in rat myocardial infarction. Mol Imaging Biol 17: 76-86, 2015.

37. Hendrikx G, De Saint-Hubert M, Dijkgraaf I, Bauwens M, Douma K, Wierts R, Pooters I, Van den Akker NM, Hackeng TM, Post MJ, et al: Molecular imaging of angiogenesis after myocardial infarction by ${ }^{111} \mathrm{In}-\mathrm{DTPA}-\mathrm{cNGR}$ and ${ }^{99 \mathrm{~m}} \mathrm{Tc}$-sestamibi dual-isotope myocardial SPECT. EJNMMI Res 5: 2, 2015.

38. Zheng K, Liang N, Zhang J, Lang L, Zhang W, Li S, Zhao J, Niu G, Li F, Zhu Z, et al: ${ }^{68} \mathrm{Ga}-\mathrm{NOTA}-\mathrm{PRGD} 2 \mathrm{PET} / \mathrm{CT}$ for integrin imaging in patients with lung cancer. J Nucl Med 56: $1823-1827,2015$.

39. Wan W, Guo N, Pan D, Yu C, Weng Y, Luo S, Ding H, Xu Y, Wang L, Lang L, et al: First experience of ${ }^{18} \mathrm{~F}$-alfatide in lung cancer patients using a new lyophilized kit for rapid radiofluorination. J Nucl Med 54: 691-698, 2013.

40. Kang F, Wang S, Tian F, Zhao M, Zhang M, Wang Z, Li G, Liu C, Yang W, Li X, et al: Comparing the diagnostic potential of ${ }^{68} \mathrm{Ga}$-Alfatide II and ${ }^{18} \mathrm{~F}$-FDG in differentiating between non-small cell lung cancer and tuberculosis. J Nucl Med 57: 672-677, 2016.

41. Yu C, Pan D, Mi B, Xu Y, Lang L, Niu G, Yang M, Wan W and Chen X: ${ }^{18} \mathrm{~F}$-Alfatide II PET/CT in healthy human volunteers and patients with brain metastases. Eur J Nucl Med Mol Imaging 42: 2021-2028, 2015

42. Iagaru A, Mosci C, Shen B, Chin FT, Mittra E, Telli ML and Gambhir SS: ${ }^{18}$ F-FPPRGD2 PET/CT: Pilot phase evaluation of breast cancer patients. Radiology 273: 549-559, 2014.

43. Zhu Z, Yin Y, Zheng K, Li F, Chen X, Zhang F and Zhang X: Evaluation of synovial angiogenesis in patients with rheumatoid arthritis using ${ }^{68} \mathrm{Ga}$-PRGD2 PET/CT: A prospective proof-ofconcept cohort study. Ann Rheum Dis 73: 1269-1272, 2014.

44. HaubnerR,Finkenstedt A,Stegmayr A, RanggerC,Decristoforo C, Zoller H and Virgolini IJ: ${ }^{68} \mathrm{Ga}$ NODAGA-RGD - Metabolic stability, biodistribution, and dosimetry data from patients with hepatocellular carcinoma and liver cirrhosis. Eur J Nucl Med Mol Imaging 43: 2005-2013, 2016.

45. Sherigar JM, Gayam V, Khan A, Mukhtar O, Arefiev Y, Khalid M, Siddiqui I, Rangaraju AM, Budhathoki N, Mansour M, et al: Clinical efficacy and tolerability of direct-acting antivirals in elderly patients with chronic hepatitis C. Eur J Gastroenterol Hepatol 29: 767-776, 2017.

46. He X, Hong Y, Wang X, Zhang X, Long J, Li H, Zhang B, Chen S, Liu Q, Li H, et al: Identification and clinical significance of an elevated level of serum aminoacylase-1 autoantibody in patients with hepatitis B virus-related liver cirrhosis. Mol Med Rep 14: 4255-4262, 2016.

47. Li F, Yan H, Wang J, Li C, Wu J, Wu S, Rao S, Gao X and Jin Q: Non-invasively differentiating extent of liver fibrosis by visualizing hepatic integrin $\alpha v \beta 3$ expression with an MRI modality in mice. Biomaterials 102: 162-174, 2016.

48. Ma W, Kang F, Wang Z, Yang W, Li G, Ma X, Li G, Chen K, Zhang Y and Wang J: ${ }^{99 \mathrm{~m}} \mathrm{Tc}-$ labeled monomeric and dimeric NGR peptides for SPECT imaging of CD13 receptor in tumorbearing mice. Amino Acids 44: 1337-1345, 2013.

49. Berman JJ: Tumor classification: Molecular analysis meets Aristotle. BMC Cancer 4: 10, 2004.

50. Pantel AR and Mankoff DA: Molecular imaging to guide systemic cancer therapy: Illustrative examples of PET imaging cancer biomarkers. Cancer Lett 387: 25-31, 2017. 